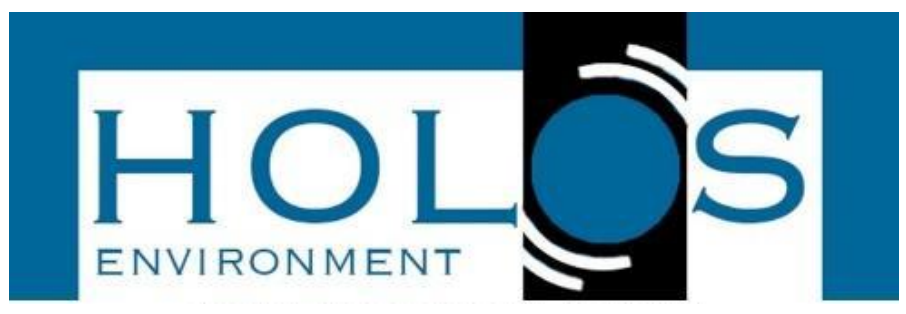

\title{
ANÁLISE DA QUALIDADE DA ÁGUA DESTINADA AO CONSUMO HUMANO EM COMUNIDADE RURAL NO MUNICÍPIO DE COXIM/MS
}

\section{ANALYSIS OF WATER QUALITY INTENDED FOR HUMAN CONSUMPTION IN A RURAL COMMUNITY IN THE COXIM/MS MUNICIPALITY}

\author{
Eriquedima Costa de Oliveira dos Santos ${ }^{1}$; Ana Carolina Correia de Oliveira Gomes ${ }^{1}$; Cleiton \\ Oliveira dos Santos ${ }^{1}$; Ana Paula Lemke ${ }^{1}$
}

Artigo recebido em: 05/05/2020 e aceito para publicação em: 13/06/2020. DOI: http:/dx.doi.org/10.14295/holos.v20i3.12394

\begin{abstract}
Resumo: O uso das águas subterrâneas para consumo humano tem aumentado, principalmente entre as populações e comunidades rurais. As águas subterrâneas estão a uma maior qualidade em relação às águas superficiais e menores custos de tratamento. A água destinada ao consumo humano deve ser potável, portando atendendo aos limites permitidos pela legislação aplicável. O presente trabalho teve como objetivo avaliar a qualidade físico, química e microbiológica de um poço tubular profundo utilizado para consumo humano em uma comunidade rural no município de Coxim (Mato Grosso do Sul). O estudo ainda analisou o Índice de Qualidade Natural das Águas Subterrâneas (IQNAS) no qual foi construído à semelhança do Índice de Qualidade de Água da National Sanitation Foundation (adaptado pela CETESB) e a Vulnerabilidade de Aquíferos utilizando a metodologia GOD que consiste em planejar três parâmetros físicos e assim gerar um índice de vulnerabilidade natural. Dos parâmetros analisados os resultados indicam que apenas Coliformes totais apresentam nos três pontos valores acima do estabelecido por lei, devendo ser investigada a causa, pois pode ser uma característica natural da água que pode ter sido contaminada na fase de construção do poço ou alguma transmissão na zona de recarga do mesmo. Os resultados do Índice de Qualidade da Água Subterrânea (IQNAS) apresentou condições ótimas e a estimativa da Vulnerabilidade do Aquífero foi classificada como insignificante.
\end{abstract}

Palavras-chave: Abastecimento. Comunidade rural. Indicadores.

\begin{abstract}
The use of groundwater for human consumption has been widely used mainly among rural populations and communities. Groundwater is linked to quality in relation to public health and environmental issues. The quality of the water is not always visible to the eyes so periodic laboratory analyzes are necessary to better classify them and check their potability for consumption. Water is classified as potable when the test values are within permitted limits. This study aimed to evaluate the physicochemical and microbiological quality of an artesian well used in a rural community in Coxim (Mato Grosso do Sul) for human consumption. The study also analyzed the Natural Groundwater Quality Index (IQNAS) which was built on the similarity to the National Sanitation Foundation Water Quality Index (adapted by CETESB) and also analyzed the Aquifer Vulnerability using the developed GOD methodology. by FOSTER \& HIRATA (1988) which consists in planning three physical parameters and thus generating a natural vulnerability index. From the analyzed parameters the results indicate that only total coliforms present values above the three allowed by law, and should be investigated, as it may be a natural characteristic of water, and may have been contaminated during the well construction phase or some transmission in the water zone. recharge and the results of the Groundwater Quality Index (IQNAS) presented optimal conditions and the estimation of Aquifer Vulnerability negligible conditions.
\end{abstract}

Keywords: Supply. Rural community. Indicators.

\footnotetext{
1 Universidade Estadual de Mato Grosso do Sul (UEMS), Coxim, MS. E-mails: (erikdma@gmail.com, anacarolinacorreiaoliveira@gmail.com, cleiton.biouems@gmail.com, anapaulalemke@yahoo.com.br)
} 


\section{INTRODUÇÃO}

O crescimento populacional, a industrialização, a ocupação territorial desorganizada e a expansão da agricultura, estão sendo responsáveis pela aceleração dos problemas de degradação dos recursos hídricos e escassez de água potável. Dentre os vários modos de se explorar a água, é possível salientar as águas subterrâneas provenientes de poços rasos ou profundos. Essa técnica tem sido comumente empregada para captação de água para o consumo humano, pois é uma fonte de abastecimento indispensável para as populações ou comunidades rurais, que não possuem acesso a rede pública de abastecimento de água (BLANK et al., 2010).

As águas subterrâneas, estão armazenadas em aquíferos livres, semiconfinado ou confinados. Os aquíferos livres são aqueles que possuem pressão atmosférica em todos os pontos e o limite superior a superfície de saturação impermeável e totalmente aflorante em toda sua extensão com recarga direta (CPRM, 2020; ABAS, 2020). Se tratando de aquíferos semiconfinados ou confinados, serão abastecidos nas zonas de recarga. Essas composições geológicas podem ainda ser divididas em três tipos: poroso, fraturado e cárstico. Os volumes de água que se encontram no subsolo, tendem a apresentar boa qualidade, melhores possibilidades de preservação contra as intervenções antrópicas ou dos diferentes tipos de uso e ocupação do solo, que possam alterar a qualidade ou a quantidade da água (ANA, 2007).

Para a captação de água subterrânea através de poços se faz importante não apenas a quantidade, mas também a qualidade da água a ser distribuída, pois a qualidade das águas subterrâneas é oferecida pela decomposição dos minerais presentes nas rochas que constituem os aquíferos (ZOBY; MATOS, 2002).

A segurança do consumo de água obedece aos padrões de potabilidade para o consumo humano no qual exige condições importantes para a saúde e bem-estar público. A lei de Qualidade da Água para Consumo Humano estabelecida na Portaria de Consolidação ํㅜ 5, de 28 de setembro de 2017 do Ministério da Saúde no qual determina os valores máximos permitidos (VMP) para que as propriedades bacteriológicas, organolépticas, físicas e químicas da água sejam classificadas como potável. De acordo com esta portaria a água para consumo humano é definida como "água potável destinada à ingestão, preparação e produção de alimentos e à higiene pessoal, independentemente da sua origem". Portanto, a água só é classificada própria para consumo quando ela atende os limites estabelecidos pela portaria do Ministério da Saúde. 
Ainda no que diz respeito à qualidade da água, quando ela é subterrânea é enquadrada conforme Resolução n³96/2008 publicada pelo Conselho Nacional de Meio Ambiente (CONAMA) que estabelece seis classes em relação aos usos essenciais, que incluem consumo humano, irrigação, recreação e dessedentação de animais (BRASIL, 2008).

As práticas humanas refletem um alto perigo em relação à contaminação das águas subterrâneas e aos aquíferos. Entre os elementos de contaminação e degradação dos recursos hídricos estão: o tratamento de esgotos domésticos e efluentes industriais, disposição de resíduos sólidos, atividades agrícola, postos de combustíveis, mineração, cemitérios, enchentes urbanas geradas pela inadequada ocupação do solo e pelo gerenciamento inadequado da drenagem urbana, ausência de coleta do resíduo urbano ou disposição final inadequada e ainda vale ressaltar os impactos indiretos no ciclo hidrológico e no clima produzidos pela impermeabilização do solo, modificações na vegetação, fauna e hidrografia, poluição do ar, dentre outros (TUCCI et al., 2001).

Apesar de estes usos poderem causar interferência na qualidade da água subterrânea, os aquíferos têm diferentes possibilidades de contaminação. Uma forma de medi-la é através do Índice de Vulnerabilidade.

De acordo com Foster e Hirata (1988), a vulnerabilidade da contaminação do aquífero é utilizada por apresentar as características específicas que determinam a fragilidade de um aquífero de ser contaminado por uma quantidade de poluentes. Existem dois métodos de vulnerabilidade desenvolvidos sendo os métodos DRASTIC (ALLER et al., 1987) e GOD (FOSTER; HIRATA 1988).

O método GOD é uma ferramenta fundamentada na estimativa do nível de acesso hidráulico da área saturada, em relação ao grau de delimitação do aquífero, da profundidade do nível estático e da capacidade de atenuação dos contaminantes (FOSTER; HIRATA 1988).

Cutrim \& Campos (2010), apontam que a utilização do método GOD é muito importante em zonas urbanas principalmente em áreas em que o abastecimento é feito por água subterrânea com ameaça de contaminação, onde as situações carecem do conhecimento da vulnerabilidade de aquífero para propor ações preventivas e corretivas adequadas.

O risco de degradação de um aquífero em um determinado local pode ser definido considerando-se a comunicação entre o volume do contaminante sobreposta ao subsolo 
como consequência das atividades humanas e a vulnerabilidade do aquífero à contaminação (FOSTER et al., 2006).

Dentre outras práticas para avaliar a qualidade das águas subterrâneas temos os Índices de Qualidade Natural das Águas Subterrâneas (IQNAS) elaborado por pesquisadores da Universidade Federal da Bahia, o qual é um instrumento matemático que permite agregar informações relevantes sobre a qualidade das águas subterrâneas através de valores numéricos, artificiais, formais e de fácil compreensão. Essa técnica corresponde a um padrão para identificação de alteração na qualidade da água, direcionando seu uso e determinando os melhores métodos de tratamento para seu uso pretendido (ENVIRONMENTASIA, 2013).

Segundo Oliveira et al. (2006), o IQNAS é um instrumento de muita utilidade para a comunidade em geral sendo preciso e de fácil interpretação que permite a avaliação estacional da qualidade da água em diversos pontos de um mesmo recurso hídrico, agregando informações sobre a qualidade das águas subterrâneas. O IQNAS foi elaborado de acordo com três estratégias básicas: 1: pesquisa do ponto de vista de especialistas, 2: uso de informações hidro químicos, e 3: utilização de técnicas estatísticas. Os autores ainda salientam que IQNAS é uma ferramenta que permite comparar seus valores para escolher a melhor qualificação do nível de qualidade do recurso hídrico, associado aos seus prováveis usos.

O IQNAS emprega os parâmetros pH, dureza, cloretos, Fluoreto, nitrato, coliformes totais, Escherichia coli e sólidos totais. A ideia do Índice de Qualidade de Uso da Água Subterrânea obedece quatro etapas: 1: escolha dos parâmetros e sua associação em grupos de modificação; 2: agregação do teor da substância analisado na amostra de água a uma esfera de acúmulo que determina a nota a ser atribuída ao parâmetro; 3: responsabilidade da nota do Grupo de Alteração; 4: determinação da importância do Índice de Qualidade de Uso da Água Subterrânea, número que representa a qualidade da água (OLIVEIRA et al., 2004).

O poço em estudo está em funcionamento desde o dia 13 de março de 2016, entretanto não há nenhum registro de análise de qualidade da água realizada anteriormente, sendo este estudo crucial para diagnosticar a água que é utilizada por quarenta e oito famílias distribuídas em uma área de 7,19 hectares na comunidade agrícola Nova Aliança, incluindo a área de reserva legal e a de preservação permanente (LIRA, 2015). 
Diante da inexistência de estudos sobre a qualidade da água e mediante a importância da análise da qualidade da água para consumo humano nessa comunidade, este trabalho teve como objetivo analisar e diagnosticar a qualidade físico-química e microbiológica da água subterrânea para consumo humano em três pontos em uma comunidade rural no município de Coxim-MS verificando sua conformidade com a legislação e aplicar o Índice de Qualidade Natural das Águas Subterrâneas (IQNAS) e o Índice de Vulnerabilidade de GOD.

\section{MATERIAL E MÉTODOS}

O presente trabalho foi realizado através de revisão bibliográfica, solicitação de banco de dados da FUNASA (Fundação Nacional da Saúde) e empresa de consultoria, coleta de água e análise dos dados.

\section{1 Área de Estudo, Data da Coleta e Método de Amostragem}

As coletas de água foram realizadas no dia 13 de maio de 2019 na comunidade agrícola Nova Aliança no município de Coxim-MS, os poços em análise fornecem água para 48 famílias dessa comunidade agrícola.

Foram utilizados frascos de polietileno para as variáveis físico-químicas, frascos de Reagente Graduado com Tampa Azul e Dispositivo Anti Gotas esterilizado para coleta de água para análise microbiológica, termômetro para medição de temperatura ambiente, prancheta com folhas e caneta para anotação das informações. No momento de cada uma das coletas foi realizada uma esterilização prévia das saídas de água, onde a mesma foi deixada aberta por 5 minutos para eliminar possíveis contaminantes e impurezas presentes no percurso da água. Em seguida foram coletadas amostras em três pontos distintos, o primeiro ponto refere-se a saída de água do poço, o segundo é a saída de água do reservatório e o terceiro é a saída de água em uma das residências conforme a delimitação dos pontos de coleta na Figura 01. O poço abrange o aquífero Aquidauana-Ponta Grossa apresentando aproximadamente 325 metros de profundidade.

Foi realizada uma coleta única para caracterização da água subterrânea e os procedimentos de coleta, conservação e análise das amostras foram realizados conforme APHA (2012). As análises de água foram realizadas em triplicata no laboratório da Universidade Federal de Mato Grosso do Sul (UFMS) campus de Campo Grande. 
Figura 01 - Localização dos pontos amostrados
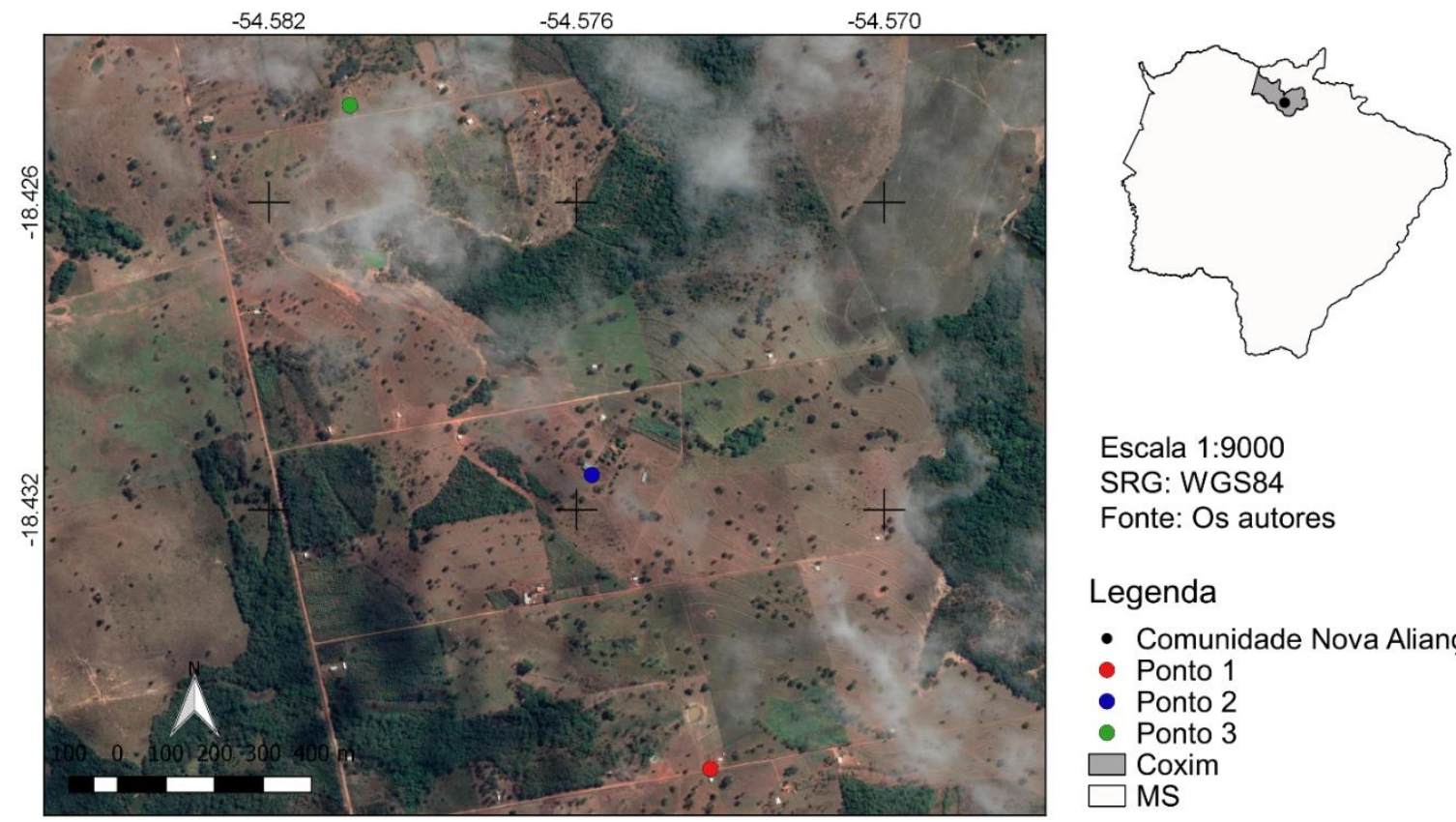

Escala 1:9000

SRG: WGS84

Fonte: Os autores

Legenda

- Comunidade Nova Aliança

- Ponto 1

- Ponto 2

- Ponto 3

$\square$ Coxim

MS

\subsection{Método de Análise dos Parâmetros}

Para análise das variáveis físicas, químicas e microbiológicas foram utilizadas as normas descritas no Standard Methods for the Examination of Water and Wastewater (APHA, 2012), conforme Tabela 01.

As variáveis físico-químicas analisadas foram: $\mathrm{pH}$, dureza, cloretos, fluoretos, nitratos e sólidos totais, enquanto as variáveis microbiológicas foram Coliformes totais e Escherichia coli.

Tabela 01 - Métodos analíticos, unidade e limite de detecção do método

\begin{tabular}{cccc}
\hline Parâmetro & Unidade & LDM & Método Analítico \\
\hline Potencial Hidrogeniônico & - & $0-14$ & SMEWW 4500-H+B \\
Dureza & $\mathrm{CaCO}_{3} \cdot \mathrm{L}^{-1}$ & 0,5 & SMEWW 2340 C \\
Cloretos & $\mathrm{mg} \cdot \mathrm{L}^{-1} \mathrm{Cl}$ & 0,5 & SMEWW 4500-Cl- \\
Fluoreto & $\mathrm{mg} \cdot \mathrm{L}^{-1} \mathrm{~F}$ & 0,1 & SMEWW 4500 F \\
Nitrato & $\mathrm{mg} \cdot \mathrm{L}^{-1} \mathrm{~N}$ & 0,01 & SMEWW 4500 \\
Coliformes totais & UFC & 1 & SMEWW 9223 B \\
Escherichia coli & UFC & 1 & SMEWW 9223 B \\
Sólidos totais & $\mathrm{mg} \cdot \mathrm{L}^{-1}$ & 0,5 & SMEWW 2540 C
\end{tabular}

Fonte: Elaborado pelos autores (2019). 


\subsection{Comparação dos resultados com a legislação vigente}

Os resultados obtidos foram comparados com os valores máximos permitidos (VMP) encontrados na resolução CONAMA 396/08, que dispõe sobre a classificação e enquadramento para águas subterrâneas, e a Portaria 2.914/11 do Ministério da Saúde, que dispõe sobre o controle e vigilância da qualidade da água para consumo humano. A comparação dos valores foi feita através de gráficos elaborados na ferramenta Excel 2010.

\subsection{Cálculo do Índice de Qualidade Natural das Águas Subterrâneas (IQNAS)}

Para a avaliação do índice de Qualidade Natural das Águas Subterrâneas foi utilizada a formulação matemática do IQNAS (Equação 01) a qual foi construída à semelhança do Índice de Qualidade de Água da National Sanitation Foundation (adaptado pela CETESB, 2013).

$I Q N A S=\prod_{i=1}^{n} q i^{w i}$

Os pesos (wi) que consideram a ação de cada parâmetro na formulação do IQNAS foram determinados com base na equação matemática da Qualidade versus Concentração do parâmetro tabela 02 .

Tabela 02 - Equações matemáticas da Qualidade versus Concentração do parâmetro

\begin{tabular}{|c|c|c|c|c|}
\hline $\begin{array}{l}\text { Parâmetros e } \\
\text { Unidades }\end{array}$ & Equações Matemáticas & $\begin{array}{c}\text { Intervalos de } \\
\text { Validade }\end{array}$ & $\mathbf{R}^{2}$ & $\begin{array}{c}\text { Pesos } \\
\left(w_{i}\right)\end{array}$ \\
\hline $\begin{array}{l}\mathrm{pH} \\
(-)\end{array}$ & $\begin{array}{c}Q_{p H}=1,7354 \times(p H)^{2} \\
Q_{p H}=16405 \times\left[(p H)^{-2,5}\right]-17\end{array}$ & $\begin{array}{c}{[2 \leq \mathrm{pH} \leq 7,34]} \\
{[\mathrm{pH} \geq 7,35]}\end{array}$ & 0,990 & 0,05 \\
\hline $\begin{array}{l}\text { Cloreto, } \\
\left(\mathrm{Cl}, \mathrm{mgL}^{-1}\right)\end{array}$ & $\begin{array}{c}Q_{C l}=100 \\
Q_{C l}=138,9 \times(C l)^{-0,19561}-(C l)^{0,42} \\
Q_{C l}=0,0\end{array}$ & $\begin{array}{c}{[\mathrm{Cl}<4,86]} \\
{[4,86 \leq \mathrm{Cl} \leq 3000]} \\
{[\mathrm{Cl}>3000]}\end{array}$ & 0,916 & 0,26 \\
\hline $\begin{array}{l}\text { Sólidos Totais, } \\
\left(\mathrm{ST}, \mathrm{mgL}^{-1}\right)\end{array}$ & $\begin{array}{c}\mathrm{QST}_{\mathrm{ST}}=79-0,167284 \times \mathrm{ST}+\mathrm{EXP}\left[(\mathrm{RT})^{0,228}\right] \\
\mathrm{QST}_{\mathrm{ST}}=27,7\end{array}$ & $\begin{array}{c}{[0 \leq \mathrm{ST} \leq 1630]} \\
{[\mathrm{ST}>1630]}\end{array}$ & 0,990 & 0,22 \\
\hline $\begin{array}{l}\text { Dureza, } \\
\text { (DUR, } \mathrm{mgL}^{-1} \text { ) }\end{array}$ & $\begin{array}{c}\text { QDUR }=100 \\
\text { QDUR }=101,1 \times \operatorname{EXP}(-0,00212 \times \text { DUR })\end{array}$ & $\begin{array}{l}{[\mathrm{DUR}<5,4]} \\
{[\mathrm{DUR} \geq 5,4]}\end{array}$ & 0,949 & 0,16 \\
\hline $\begin{array}{l}\text { Fluoreto, } \\
\left(\mathrm{F}, \mathrm{mgL}^{-1}\right)\end{array}$ & $\begin{array}{c}Q_{F}=80+21 \times F-(F)^{11,8283} \\
Q_{F}=0,0\end{array}$ & $\begin{array}{c}{[0 \leq F \leq 1,5]} \\
{[F>1,5]}\end{array}$ & 0,924 & 0,16 \\
\hline $\begin{array}{l}\text { Nitrato, } \\
\left(\mathrm{N}-\mathrm{NO}_{3}, \mathrm{mgL}^{-1}\right)\end{array}$ & $Q_{N}=100 \times \operatorname{EXP}(-0,0994 \times N)$ & {$[N \geq 0,0]$} & 0,993 & 0,15 \\
\hline & Soma total dos pesos & & & 1,00 \\
\hline
\end{tabular}


O IQNAS (Índice de Qualidade Natural das Águas Subterrâneas) é apresentado por um número entre 0 e 100, divido em quatro (04) classes, onde de 0 a 36 determina as águas como padrão inaceitável, de 37 a 51 aceitável, de 52 a 79 boa e de 80 a 100 ótima conforme tabela 03.

Tabela 03 - Fórmula e Classificação da Qualidade da Água Subterrânea

\begin{tabular}{|c|c|c|}
\hline Parâmetros & Equação & $\begin{array}{c}\text { Classificação da Qualidade da Água } \\
\text { Subterrânea }\end{array}$ \\
\hline $\begin{array}{c}\text { Cloreto } \\
\mathrm{pH} \\
\text { Resíduos Totais } \\
\text { Dureza } \\
\text { Flúor } \\
\text { Nitrato }\end{array}$ & IQNAS $=\prod_{i=1}^{n} q i^{w i}$ & $\begin{array}{c}80-100=\text { Ótima } \\
52-79=\text { Boa } \\
37-51=\text { Aceitável } \\
20-36=\text { Imprópria }\end{array}$ \\
\hline
\end{tabular}

\section{5 Índice de Vulnerabilidade}

Para determinar a vulnerabilidade do aquífero foi utilizada a metodologia de GOD desenvolvida por FOSTER e HIRATA (1988). Essa metodologia consiste em analisar três parâmetros físicos e assim gerar um índice de vulnerabilidade natural onde: G: é o tipo de ocorrência da água subterrânea (livre, confinado, semi-confinado); O: São litologias gerais dos aquíferos e D: é a profundidade do nível do lençol freático.

Esse método é muito utilizado por solicitar um menor número de parâmetros, oferecendo assim maior rapidez nos resultados, como apresentado na Figura 02 (ARAUJO et al., 2017).

Através do método GOD, foi possível classificar a classe de vulnerabilidade do aquífero de acordo com as cinco diferentes classificações de vulnerabilidade natural à contaminação do aquífero conforme Quadro 01: desprezível, baixa, moderada, alta e extrema. 
Figura 02- Método de vulnerabilidade GOD

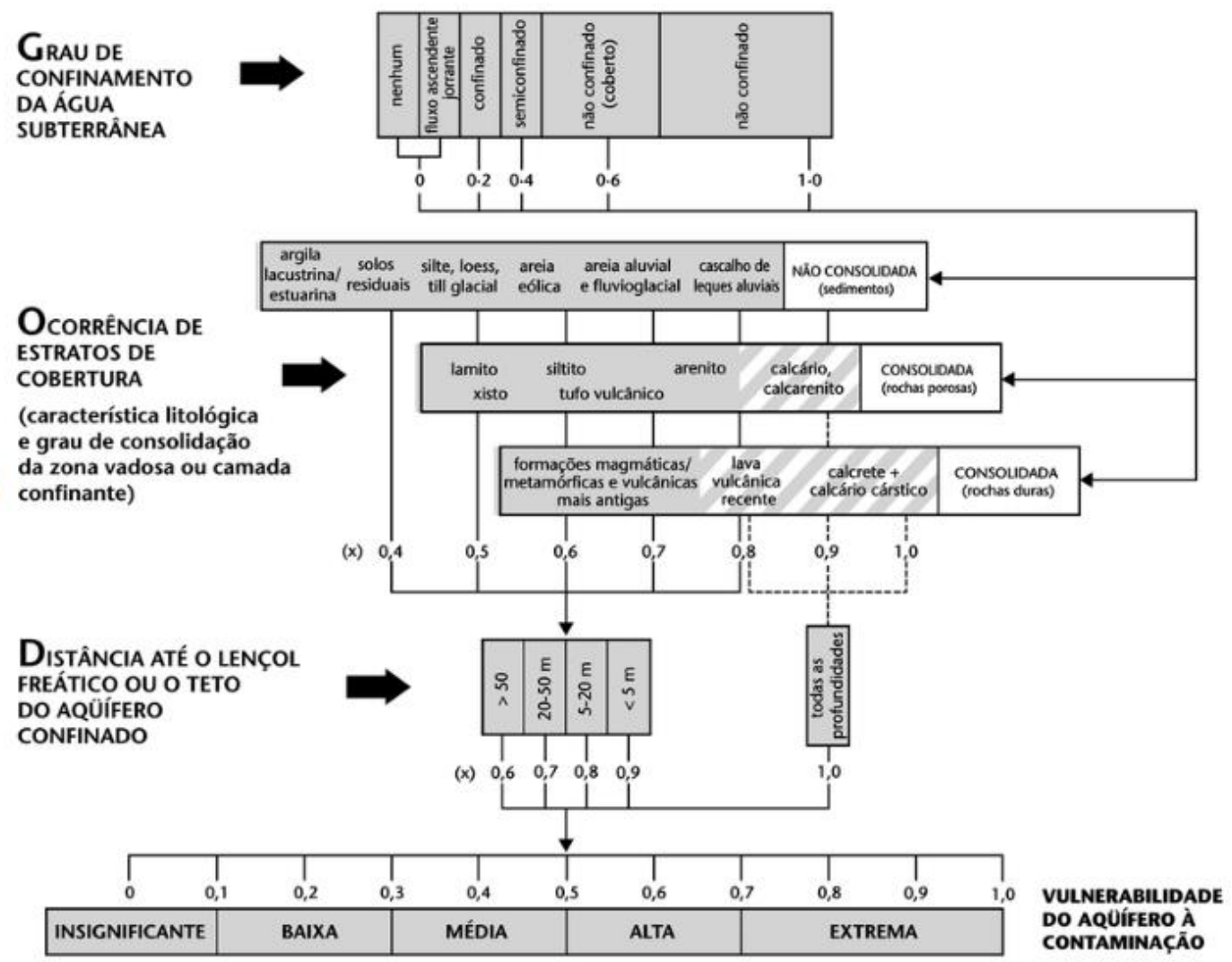

Fonte: Modificado de Foster \& Hirata 1988.

Quadro 01 - Classes de Vulnerabilidade do Aquífero

\begin{tabular}{|c|c|}
\hline Classes de Vulnerabilidade & Definição Prática \\
\hline Extrema & $\begin{array}{c}\text { Vulnerabilidade a muitos poluentes, } \\
\text { incluindo os rapidamente degradáveis em } \\
\text { muitos cenários de contaminação. }\end{array}$ \\
\hline Alta & $\begin{array}{c}\text { Vulnerável a muitos poluentes, exceto } \\
\text { aqueles muito pouco moveis e pouco } \\
\text { persistente. }\end{array}$ \\
\hline Moderada & $\begin{array}{c}\text { Vulnerável a alguns poluentes e somente } \\
\text { quando continuamente lançados. }\end{array}$ \\
\hline Baixa & $\begin{array}{c}\text { Somente Vulnerável a contaminantes } \\
\text { conservativos em longo prazo, quando } \\
\text { continuamente e amplamente lançados. }\end{array}$ \\
\hline Desprezível & $\begin{array}{c}\text { Não Vulnerável, exceto em locais restritos } \\
\text { que permitam o fluxo vertical (Ex: zonas de } \\
\text { fraturas). }\end{array}$ \\
\hline
\end{tabular}

Fonte: Modificado de Foster (1998); Foster et al. (2002).

\section{RESULTADOS E DISCUSSÃO}

Das amostras coletadas foram obtidos os resultados dispostos no Quadro 02. 
Quadro 02 - Comparação dos resultados das análises com a Resolução CONAMA 396/08 e Portaria Ministério da Saúde 2.914/11 *VMP Valor máximo permitido

\begin{tabular}{|c|c|c|c|c|c|c|}
\hline PARÂMETRO & Ponto 1 & Ponto 2 & Ponto 3 & Unidade & $\begin{array}{c}\text { VMP* } \\
\text { VMP* } \\
\text { CONAMA } \\
\text { 396/08 }\end{array}$ & $\begin{array}{c}\text { PORTARIA } \\
\text { Ministério da } \\
\text { Saúde } \\
\mathbf{2 . 9 1 4 / 1 1}\end{array}$ \\
\hline pH & 6,9 & 7 & 6,94 & - & Não consta & 6,0 a 9,5 \\
\hline Dureza & 23,7 & 22,6 & 24,7 & $m g \cdot \mathrm{CaCo}_{3} \cdot L^{-1}$ & Não consta & 500 \\
\hline Cloretos & $<1,0$ & $<1,0$ & $<1,0$ & $m g \cdot L^{-1}$ & 250.000 & 250 \\
\hline Fluoreto & $<1,0$ & $<1,0$ & $<1,0$ & $m g \cdot L^{-1}$ & 1.500 & 1,5 \\
\hline Nitrato & 0,6 & 0,6 & 0,8 & $m g \cdot L^{-1}$ & 10.000 & 10 \\
\hline $\begin{array}{c}\text { Coliformes } \\
\text { Totais }\end{array}$ & $2.419,60$ & 1986,3 & 488,4 & $U F C \cdot 100 m l^{-1}$ & $\begin{array}{c}\text { Ausentes em } \\
100 \mathrm{ml}\end{array}$ & $\begin{array}{c}\text { Ausentes em } \\
100 \mathrm{ml}\end{array}$ \\
\hline E. coli & Ausente & Ausente & Ausente & $U F C \cdot 100 m l^{-1}$ & $\begin{array}{c}\text { Ausentes em } \\
100 \mathrm{ml}\end{array}$ & $\begin{array}{c}\text { Ausentes em } \\
100 \mathrm{ml}\end{array}$ \\
\hline Sólidos Totais & 39 & 47 & 35 & $m g \cdot L^{-1}$ & 1.000 .000 & 1000 \\
\hline
\end{tabular}

Fonte: Elaborado pelos autores (2019).

No Quadro 02 é possível observar que os resultados dos parâmetros nos três pontos estão de acordo com os valores máximos permitidos tanto na Resolução CONAMA 396/08 como na Portaria 2914/11 do Ministério da saúde exceto o parâmetro Coliformes Totais que apresentam grandes variações nos três pontos com valores acima do permitido em ambas as legislações, assim pode-se concluir que apesar de ser a primeira vez que se realizou as análises dos oitos parâmetros mensurados apenas 1 apresenta-se em inconformidade com as legislações supracitadas.

Segundo Menezes (2009) as justificativas do indício dos coliformes em águas profundas dos poços acontecem muitas vezes na fase de construção, pois às vezes eles são escavados e não são adequadamente vedados fazendo com que a contaminação esteja partindo das próprias canalizações do mesmo, ou até mesmo recebem poluentes provenientes da infiltração de água em áreas onde se predomina atividades de pecuária, ou recebem efluentes contaminados por se encontrarem próximos de fossas sépticas.

De acordo com os dados disponíveis, o perfil construtivo do poço possui impermeabilização (Figura 03), isto mostra que a contaminação pode ter ocorrido na fase de construção, ou conforme relatado por Menezes (2009) pode ser uma característica natural da água ou alguma contaminação na zona de recarga do aquífero. 
Figura 03 - Perfil Construtivo e Litológico do poço da Comunidade Nova Aliança em Coxim/MS

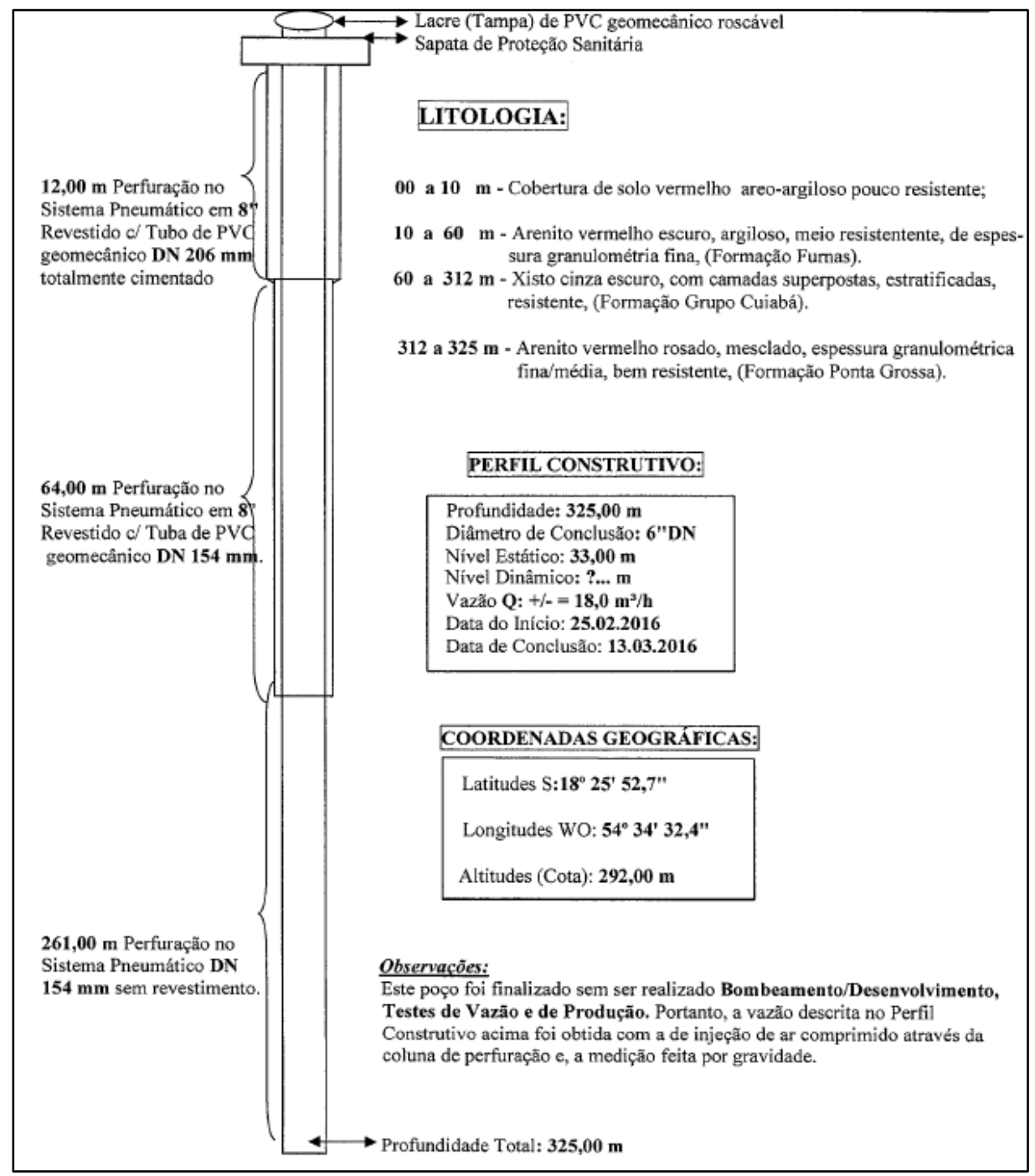

Fonte: FUNASA (2016).

As alterações nos valores do parâmetro Coliformes totais nos três pontos não significa que o poço não apresenta agua de boa qualidade, pois de acordo com Lima (2009) as águas dos aquíferos profundos estão menos susceptíveis a contaminação que as de aquíferos rasos devido ao manto que reveste toda a estrutura do poço servindo assim como uma proteção ao mesmo, portanto o poço analisado é considerado um aquífero profundo por apresenta aproximadamente 325 metros de profundidade apresentando menor índice de contaminação.

A contagem dos coliformes totais apresentada nos três pontos é considerada como parâmetro indicador da possibilidade da existência de microrganismos patogênicos, isso indica que as bactérias coliformes na água potável pode indicar uma possível presença de organismos nocivos, causadores de doenças, pois de acordo com a Portaria 2.914 /2011 (BRASIL, 2019) e com a Resolução CONAMA 396/2008 a água para ser considerada 
potável deve apresentar ausência de coliformes totais e termotolerantes em $100 \mathrm{ml}$ de água.

Em relação ao potencial hidrogeniônico $(\mathrm{pH})$ pode se observar que o mesmo atende aos valores máximos permitidos na Portaria 2.914/2011 e na Resolução CONAMA $396 / 2008$ na qual nada consta em relação à valores de pH. Cabe ressaltar que o pH caracteriza a intensidade das condições de acidez, alcalinidade ou neutralidade de um meio qualquer ou meio líquido.

Segundo Gasparotto (2011) as variações nos valores de pH diante as águas superficiais ou subterrâneas podem ter indícios das ações humanas como lançamento de efluentes domésticos e industriais ou indícios naturais como fotossíntese e dissolução de rochas. $\mathrm{O}$ autor ainda destaca que o $\mathrm{pH}$ pode ser visto como uma dos aspectos ambientais mais importantes, sendo um dos mais difíceis de se analisar, pois essa complicação é decorrente dos mais variados fatores que podem influenciá-lo, podendo estar associado a fontes de poluição através de lançamentos individualizados sendo facilmente identificados ou lançamento específico de difícil controle e identificação.

A dureza consiste na presença de sais de cálcio e magnésio causado pela lavagem da camada superficial do solo através do escoamento superficial da água. Segundo Malakootian et al. (2010) as águas que apresentam valores maiores que o permitido de dureza podem ocasionar problemas nas tubulações de água quente, em equipamentos de cozinha, e de abastecimento de águas dentre outros. A dureza pode ser classificada em temporária e permanente na qual a dureza temporária refere-se à presença de carbonatos e bicarbonatos de cálcio e magnésio e ainda resiste aos sabões podendo ser removida pela fermentação porque os bicarbonatos, pela influência do calor, se dissolvem em gás carbônico, água e carbonatos indestrutíveis, os quais precipitam. Já a dureza permanente refere-se aos sulfatos, cloretos e nitratos de cálcio e magnésio na qual também resiste à ação dos sabões não podendo ser removida pela fermentação (MENEZES, 2009).

A análise de cloretos é uma forma de obter um importante resultado, pois ele nos permite encontrar o teor de sal presente na água de uma forma rápida e fácil (SANTOS, 2010). Nos três pontos os resultados de cloretos apresentaram valores dentro do permitido em ambas às legislações revelando que a salinidade da água, neste caso, está apta ao consumo. De acordo com Andrade e Macedo (2008), os cloretos em valores altos podem provocar desgaste em caldeiras e tubulações, equipamentos aço inox e formar resíduos no interior de tubulações pisos, paredes ou equipamentos devido à liberação de substâncias dissolvidas na água que se transformam em sólidos indestrutíveis. 
É possível saber o grau de mineral ou obter evidências de poluição através da quantidade de cloretos na água, além disso, é importante ressaltar que os cloretos podem ser causados pelas técnicas de fertilização do solo, no qual o procedimento da lavagem do solo pelo escoamento superficial causado pela chuva afetam os solos e também as águas subterrâneas por serem atingidos com resíduos doméstico e industrial disposto inadequadamente (LAJEADO, 2016).

Os resultados do fluoreto indicam que os valores estão de acordo com os valores máximos permitidos podendo ser consumidas pelas pessoas, pois os fluoretos dentro dos valores permitidos são benéficos aos ossos e à saúde dos dentes (OMS, 1997). Segundo a Organização Mundial da Saúde (1997), o flúor em menores volumes em água potável apresentam resultados positivos em relação aos dentes, mas em valores exagerado na água de consumo, ou em outras fontes, podem dar provocar efeitos diversos em relação à saúde.

O nitrato na água subterrânea acima dos valores máximos permitidos indica evidência de alguma atividade antrópica, podendo esta estar relacionadas às fontes pontuais como esgotos ou difusas como resíduos da agricultura (MENEZES, 2009). Os resultados indicam que nos três pontos não há sinais de poluição proveniente da ação humana, pois o mesmo se encontra de acordo com os valores máximos permitidos.

Quanto aos aspectos microbiológicos, a bactéria Escherichia coli (E. coli) mostrouse ausente nos três pontos analisados e isso indica que esse parâmetro está de acordo com as legislações mencionadas. Segundo Deberdt (2003), os resultados bacteriológicos são os mais importantes parâmetros a serem analisados, pois são eles que determinam a verdadeira qualidade da água para consumo humano. O autor supracitado ainda afirma que a E. coli é um parâmetro que indica o grau de contaminação fecal que são bactérias eliminadas com as fezes de organismos de sangue quente e são essas fezes de pessoas doentes que transportam, para as águas ou para o solo, os micróbios causadores de doenças.

Os sólidos totais referem-se a toda matéria que permanece como resíduo no envoltório após a evaporação, secagem ou decomposição térmica de um determinado volume de amostra (CETESB, 2009), portanto os resultados dos sólidos totais nos três pontos estão de acordo com os valores máximos permitidos nas legislações, isso indica que não houve concentração de resíduos na água. 
Segundo Brasil (2009) de maneira indireta os sólidos influenciam a vida aquática, pois com a presença dos sólidos eles dominam o aquecimento da água e ainda impedem a introdução da luz no que diminui o volume de oxigênio dissolvido no meio.

A distribuição de água para consumo humano deve atender aos padrões de potabilidade, e deve ser constituindo de atividades e políticas públicas que garantam água adequada ao consumo humano prevenindo a mortalidade e doenças (SILVA et al., 2003). As águas que não atendem ao padrão de potabilidade precisam ser evitadas através das informações esclarecidas a população promovida por meio do poder público federal, estadual e municipal, secretárias de educação e meio ambiente através de campanhas, palestras comunitárias e escolares em relação à preservação e uso de água de poço, apresentando os riscos e perigos atuais e futuros, portanto essas águas fora do padrão são consideradas águas impróprias para consumo (VASCONCELOS, 2006)

Através do banco de dados oferecidos pela FUNASA e empresa de consultoria e através dos resultados das análises pode-se aplicar o Índice de Qualidade de Água Subterrânea (IQNAS) no qual os valores de qualidade da água subterrânea para cada parâmetro químico escolhido (Qi) foi elevado ao peso atribuído a cada variável (wi) em cada ponto analisado, dessa forma obtivem: IQNAS $=\prod_{i=1}^{n} q i^{{ }^{w i}}$

Os resultados do Índice de Qualidade de Água subterrânea (IQNAS) expressos no quadro 03 apresentam a classificação da água em cada ponto coletado.

Quadro 03 - Resultado do Índice de Qualidade de Água subterrânea (IQNAS)

\begin{tabular}{|c|c|c|c|c|c|c|c|}
\hline Parâmetro & Q1 & Q2 & Q3 & wi & $q i^{\wedge} \mathbf{w i}$ & $q 2^{\wedge} w i$ & $q^{3^{\wedge}} \mathbf{w i}$ \\
\hline$p H$ & 82,62 & 85,03 & 83,58 & 0,05 & 1,246964988 & 1,24875894 & 1,24768547 \\
\hline Dureza & 96,15 & 96,37 & 95,94 & 0,16 & 2,076212905 & 2,07697227 & 2,0754867 \\
\hline Cloretos & 100,0 & 100,0 & 100,0 & 0,26 & 3,311311215 & 3,31131121 & 3,31131121 \\
\hline Fluoreto & 99,9 & 99,9 & 99,9 & 0,16 & 2,088961703 & 2,0889617 & 2,0889617 \\
\hline Nitrato & 94,21 & 94,21 & 92,36 & 0,15 & 1,977491159 & 1,97749116 & 1,97161716 \\
\hline Sólidos Totais & 82,5 & 82,22 & 82,63 & 0,22 & 2,640096909 & 2,63812302 & 2,64101158 \\
\hline IQNAS & & & & & 93,5 & 93,6 & 93,3 \\
\hline Classificação & & & & & Ótima & Ótima & Ótima \\
\hline
\end{tabular}

Fonte: elaborado pelos autores (2019).

Como pode-se observar no Quadro 03, o Índice de Qualidade de Água Subterrânea (IQNAS) nos três pontos obtiveram classificação Ótima. O índice de qualidade de água é uma técnica que utiliza cálculos para modificar vários parâmetros em uma única dimensão 
na qual caracteriza o nível de qualidade da água (SÁNCHEZ et al., 2007; CCME, 2001B; FERREIRA; IDE, 2001).

O uso de um Índice de Qualidade da Água é uma direção a ser seguida em acompanhamento e monitoramento da qualidade da água para que descrevam e representem de forma compreensível e significativa o estado atual e as vertentes dessa qualidade, portanto esta ferramenta auxilia na avaliação dos resultados para a tomada de decisões em relação aos recursos hídricos (MOLOZZI et al., 2005; AURELIANO et al., 2005; PINHEIRO, 2004 apud MOLOZZI et al., 2005).

Um índice de qualidade, criado com base em indicadores de qualidade da água subterrânea é representado por um único número, e esse valor é associado a uma cor, permitindo assim avaliar e caracterizar as condições de qualidade dos mananciais superficiais e subterrâneos, para os diversos usos como consumo humano, indústria alimentícia, indústria em geral, irrigação, dessedentação de animais e recreação (PORTO, 1991).

Para atingir o último objetivo do estudo o trabalho teve como aproveitamento a elaboração de uma análise da vulnerabilidade do aquífero a partir do método GOD conforme o Quadro 04.

Quadro 04 - Estimativa da vulnerabilidade do aquífero

\begin{tabular}{|c|c|c|c|}
\hline G & $\mathbf{0}$ & $\mathbf{D}$ & $\begin{array}{c}\text { Índices Finais De } \\
\text { Vulnerabilidade }\end{array}$ \\
\hline \multirow{2}{*}{0.2} & 0.7 & 0.6 & $\begin{array}{c}\text { G } \times 0 \times \mathrm{D} \\
0.2 \times 0.7 \times 0.6= \\
0,084\end{array}$ \\
\hline \multicolumn{3}{|c|}{ Vulnerabilidade } & Desprezível \\
\hline
\end{tabular}

Fonte: elaborado pelos autores (2019).

Como se pode observar no quadro 04 o tipo de ocorrência da água subterrânea (G) recebe peso 0.2 por ser um poço confinado e em relação as litologias do aquífero (O) 0 peso atribuído é 0.7 por apresentar características de arenito nas zonas não saturadas ou camadas confinantes (Figura 3), já a profundidade do nível do lençol freático recebe (D) peso 0.6 por apresentar uma profundidade maior que 50 metros. Assim através do método de GOD o resultado do cálculo apresenta classe de vulnerabilidade desprezível, ou seja, o aquífero se encontra não vulnerável.

A ideia da vulnerabilidade refere-se ao fato de que o ambiente físico dos aquíferos oferece certa proteção às águas subterrâneas contra contaminações de diversas origens 
(LOPES et al., 2012), portanto a vulnerabilidade calculada no presente trabalho diz respeito à proteção geológica sobreposta ao aquífero analisado. Segundo Hirata \& Ferreira (2001), a análise da vulnerabilidade representa uma ferramenta para a preservação da qualidade das águas subterrâneas, possibilitando orientar quais as áreas são mais adequadas e menos expostas as instalações e práticas de atividades potencialmente poluidoras.

A utilização do método de GOD é uma importante técnica utilizada para analisar o abastecimento de água em áreas urbanas que em grande parte o abastecimento é realizado por água subterrânea com risco de contaminação por não realizarem análises periodicamente (CUTRIM; CAMPOS, 2010).

\section{CONCLUSÕES}

O IQNAS nos três pontos apresentou qualidade ótima e a vulnerabilidade do aquífero é desprezível. Dos parâmetros analisados o que obteve valores acima do permitido por lei nos três pontos investigados foi coliformes totais, devendo ser investigado, pois pode ser uma característica natural da água, ter sido contaminada na fase de construção do poço ou alguma transmissão na zona de recarga do mesmo.

\section{REFERÊNCIAS}

ALLER, L.; BENNETT, T.; LEHR, J.H.; PETTY, R.; HACKETT, G. Drastic: a standardized system for evaluating groundwater pollution potential using hydrogeologic settings. US E.P.A, EPA/600/287/035, 1987, EUA.

ANA - Agência Nacional de Águas. Disponibilidade e demanda de recursos hídricos no Brasil. Caderno de Recursos Hídricos, 2007. Agência Nacional de Águas. Disponível em https://www.ana.gov.br/AcoesAdministrativas/CDOC/CatalogoPublicacoes 2007.asp. Acesso em: 16 jul. 2019.

ANDRADE, N.J.; MACEDO, J.A.B. Higienização na indústria de alimentos. São Paulo: Livraria Varela, 2008. p. 182.

ABAS. Águas subterrâneas: o que são? Disponível em: https://www.abas.org/aguassubterraneas-o-que-sao/\#ind21. Acesso em: 16 jul. 2019.

APHA. Standard methods for the examination of water and wastewater. 20. ed. Washington.=: American Publish Health Association, American Water Works Association, Water Environmental Federation, 2012.

ARAUJO et al. Vulnerabilidade natural e perigo de contaminação do sistema aquífero dunas na região norte do município de Aquiraz, Ceará. Revista do Instituto Geológico, São Paulo, v. 38, n. 2, p. 37-48, 2017. https://doi.org/10.5935/0100-929X.20170008 
AZEVEDO NETTO, J. M. Cronologia do abastecimento de água até 1970. Revista DAE, v. 44, n.137, 1984.

BLANK et al. Caracterização físico-química e microbiológica de água de poços rasos do bairro três vendas, Pelotas-RS. In: ENPOS-II MOSTRA CIENTÍFICA, 12., 2010. [Anais...]. Pelotas, RS, 2010.

BRASIL. Ministério do Meio Ambiente. Conselho Nacional do Meio Ambiente (CONAMA). Resolução CONAMA nํ396, 08 de abril de 2008. Dispõe sobre a classificação e diretrizes ambientais para o enquadramento das águas subterrâneas e dá outras providências. Diário Oficial da União, Brasília, 2008.

BRASIL. Ministério do Meio Ambiente. Conselho Nacional do Meio Ambiente. Resolução no 357, de 17 de março de 2005. Brasília, 2005. Disponível no site http://www.crq4.org.br/downloads/resolucao357.pdf. Acesso em: 01 set. 2009.

BRASIL. Portaria no 2.914, de 12 de dezembro de 2011. Dispõe sobre os procedimentos de controle e de vigilância da qualidade da água para consumo humano e seu padrão de potabilidade. Diário Oficial da República Federativa do Brasil, Brasília, DF, 14 dez. 2011.

CETESB - Companhia de Tecnologia de Saneamento Ambiental do Estado de São Paulo. Índice de qualidade da água, 2007. Disponível em: https://cetesb.sp.gov.br/aguas-interiores/wpcontent/uploads/sites/12/2013/11/Ap\%C3\%AAndice-C-\%C3\%8Dndices-de-Qualidade-das\%C3\%81guas-2.pdf. Acesso em: 24 out. 2019.

CPRM. Aquíferos. Disponível em: http://www.cprm.gov.br/publique/Redes-Institucionais/Rede-deBibliotecas---Rede-Ametista/Aquiferos-1377.html. Acesso em: 16 jul. 2019.

CUTRIM, A.O.; CAMPOS, J.E.G. Avaliação da vulnerabilidade e perigo à contaminação do aquífero furnas na cidade de Rondonópolis com a aplicação dos métodos GOD e POSH. Revista Geociências, v. 29, n. 3, p. 401-411, 2010.

DEBERDT, Jean André. Análise da água. Programa pró ciência. Resumos do II Congresso Brasileiro de Agroecologia. Revista Brasileira Agroecologia, v.2, n.1, fev. 2007.

ENVIRONMENTASIA. Thailandia Society of Higher Education Institutes on Environment. Groundwater Quality Index for Water Supply Production. EnvironmentAsia, p.18-23, 2013. Disponível em: http://www.thaiscience.info/Journals/Article/ENVA/10895365.pdf. Acesso em: 24 out. 2019.

FOSTER, S.; HIRATA, R.; GOMES, D.; D’ELIA, M.; PARIS, M. 2006. Groundwater quality protection: a guide for water service companies, municipal authorities and environment agencies. World Bank, GWMATE, Washington, 104 p. Disponível em:

http://documents.worldbank.org/curated/pt/913221468028147970/pdf/250710PUB00BOX334116B 01PUBLIC1.pdf. Acesso em: 24 out. 2019.

FOSTER, S.; HIRATA, R.C.A.Groundwater pollution risk evaluation: the methodology using available data. CEPIS/PAHO/WHO, Lima, 1988. 78 p.

GASPAROTTO, F. A. Avaliação ecotoxicológica e microbiológica da água de nascentes urbanas no município de Piracicaba-SP. Piracicaba: Universidade de São Paulo, 2011.

HIRATA, C.A.R.; FERREIRA, L.M.R. 2001. Os Aquíferos da Bacia Hidrográfica do Alto Tietê: disponibilidade hídrica e vulnerabilidade à poluição. Revista Brasileira de Geociências, v. 31 , 
p.43-50. Disponível em: http://www.ppegeo.igc.usp.br/index.php/rbg/article/view/10443. Acesso em: 24 out. 2019.

\section{LAJEADO. F. F. Análise comparativa de águas de reuso industrial na região do Vale do Taquari, jun. 2016}

LIMA, L.A. Vulnerabilidade de aquíferos fraturados: Bacia Hidrográfica do Rio São Domingos, São José de Ubá/RJ. 2009. 116f. Dissertação (Mestrado em Geologia) - Instituto de Geociências, Universidade Federal do Rio de Janeiro, Rio de Janeiro, 2009.

LIRA, A. Coxim: 48 famílias concretizam sonho e recebem título definitivo de propriedade. Disponível em: http://www.agraer.ms.gov.br/coxim-48-familias-concretizam-sonho-e-recebemtitulo-definitivo-de-propriedade/. Acesso em: 12 nov. 2019.

LÖBLER, C.A.; SILVÉRIO, J.L.; TERRA, L.G. Mapeamento da vulnerabilidade das águas subterrâneas e uso do solo na área urbana do município de Nova Palma, RS. Ciência e Natura, v. 36, n. 2, p. 587-592, 2014. https://doi.org/10.5902/2179460X14843

LOPES, J.L.S.; CESTARO, L.A.; KELTING, F.M.S. 2012. Zoneamento ambiental como instrumento de uso e ocupação do solo do município de Aquiraz-CE. Boletim Goiano de Geografia, v. 32, n. 1, p. 93-104. Disponível em:

https://www.redalyc.org/pdf/3371/337127361006.pdf. Acesso em: 24 out. 2019. https://doi.org/10.5216/logg.v32i1.18958

MALAKOOTIAN, M.; MANSOORIAN, H. J.; MOOSAZADEH, M. Performance evaluation of electrocoagulation process using iron-rod electrodes for removing hardness from drinking water. Desalination, v. 255, n. 1-3, p. 67-71, 2010. https://doi.org/10.1016/j.desal.2010.01.015

MENEZES, J. M. Índice de Qualidade de água subterrânea aplicado em área de aquíferos cristalinos com uso agrícola: Bacia do Rio São Domingos - RJ. Rio de Janeiro: UFRJ/ PPGI, 2009.

MOLOZZI, J.; DIAS, A. S.; PINHEIRO, A.; SILVA, M. R. Qualidade da Água Utilizada na Atividade de Rizicultura: Caso do Município de Gaspar/SC. In: SIMPÓSIO BRASILEIRO DE RECURSOS HÍDRICOS, 16., 2005, João Pessoa. [Anais...] João Pessoa: ABRH, 2005. 1 CD-ROM.

OLIVEIRA, I. B.; NEGRÃO, F. I.; ROCHA, T. S. Determinação do índice de qualidade da água subterrânea - IQAS, com base nos dados de poços tubulares do estado da Bahia: áreas piloto: Recôncavo e Platô de Irecê - Cuiabá. In: CONGRESSO BRASILEIRO DE ÁGUAS SUBTERRÂNEAS, 13., 2004. [Anais...]. Cuiabá, out. 2004.

OLIVEIRA, I. B.; NEGRÃO, F. I.; SILVA, A. G. L. S.. Aplicação do índice de qualidade natural da água subterrânea (IQNAS) para os domínios hidrogeológicos do estado da Bahia. In:

CONGRESSO BRASILEIRO DE ÁGUAS SUBTERRÂNEAS, 14., 2006. [Anais...]. Curitiba, PR, 2006.

ORGANIZAÇÃO MUNDIAL DA SAÚDE (OMS). Objetivos dessa organização, suas ações práticas, história, entre outras informações, 1997. Disponível em: https://www.infoescola.com/saude/organizacao-mundial-de-saude-oms. Acesso em: 21 out. 2019.

PORTO, R. L. L. Estabelecimento de parâmetros de controle da poluição. In: PORTO, R. L. L. BRANDO, S. M., CLEARY, R. W. et al. Hidrologia ambiental. São Paulo: Associação brasileira de Recursos Hídricos, ABRH, 1991. 
PORTO, R. L. L. Estabelecimento de parâmetros de controle da poluição. In: PORTO, R. L. L., BRANDO, S. M., CLEARY, R. W. et al. Hidrologia ambiental. São Paulo: Associação brasileira de Recursos Hídricos, 1991.

SÁNCHEZ, E.; COLMENAREJO, M.F.; VICENTE, J., RUBIO, A.; GARCÍA, M.G., TRAVIESO, L.; BORJA, R. Use of the Water Quality Index and Dissolved Oxygen Deficit as Simple Indicators of Watersheds Pollution. Ecological Indicators. v. 7, n. 2, p. 315-328, 2007.

https://doi.org/10.1016/i.ecolind.2006.02.005

SANTOS, F. G.; FELICIANO, S. Departamento de Ciências Biológicas Faculdades Integradas de Ourinhos - FIO/FEMM, 2008.

SILVA, L.M; SOUZA, E.H; ARREBOLA, T.M; JESUS, G.A. Ocorrência de um surto de hepatite A em três bairros do município de Vitória (ES) e sua relação com a qualidade da água de consumo humano. Ciênc. Saúde coletiva, v.14, n.6, p. 2163-2167, 2009. https://doi.org/10.1590/S1413$\underline{81232009000600023}$

TUCCI, C.E.M., HESPANHOL, I. e CORDEIRO NETTO, O. de M. A Gestão da água no Brasil: uma primeira avaliação da situação atual e das perspectivas para 2025. Impresso, 2001.

UNITED STATE FEDERAL COUNCIL SCIENCE AND TECHNOLOGY - (Ciência e Tecnologia do Conselho Federal dos Estados Unidos). IT 115: irrigação e drenagem, maio 2007.

VASCONCELOS, S. M. S. Recarga do Aquífero Dunas/Paleodunas. Fortaleza - CE.Tese (Doutorado em Geociências) - Universidade de São Paulo, 1999. 100p.

VASCONCELOS; T.A. Estudo físico-químico e microbiológico de águas de poços tubulares da cidade de manaus. Dissertação (Mestrado) - Universidade Federal do Amazonas, 2006.

ZOBY, J.L.G. \& MATOS, B. Águas subterrâneas no Brasil e sua inserção na Política Nacional de Recursos Hídricos. In: CONGRESSO BRASILEIRO DE ÁGUAS SUBTERRÂNEAS, 12., Florianópolis, 2002. [Anais...]. Florianópolis: ABAS, 2002. CD-ROM. 